\title{
TÉCNICAS DA AÇÃO: EM TORNO DA DIALÉTICA ENTRE O USO CORPORATIVO DO TERRITÓRIO E AS AÇÕES DOS MOVIMENTOS DE SEM-TETO
}

\author{
CARLOS EDUARDO NOBRE ${ }^{1}$
}

Universidade Estadual de Alagoas

Resumo: Este artigo busca discutir como atualmente a cidade gera um uso seletivo e corporativo do território (SANTOS, 2005) pelos mercados fundiário e imobiliário, ao criar artificialmente uma situação de escassez habitacional através do uso rentável e especulativo de vazios urbanos potencialmente úteis à moradia. Ao mesmo tempo, buscamos demonstrar como esse processo corrobora a emergência de movimentos de sem-teto que passam a utilizar os vazios urbanos subversivamente, através de ocupações programadas, no intuito de restaurar direitos e romper com a lógica de apropriação privada da cidade pelo grande capital. Nosso objetivo principal é apontar argumentos para a necessária contextualização das práticas territoriais dos sem-teto a partir do uso seletivo e corporativo da cidade pelos agentes hegemônicos. Para tanto destacamos três práticas territoriais distintas, porém complementares, que afetariam o direito à moradia e reforçariam o uso corporativo do território. Por fim, concluímos que as ações dos semteto, como ações contra-hegemônicas (SANTOS, 2008a), resultam do próprio uso corporativo do território pelo capital, de modo que o meio construído se torna base às operações conflituosas oriundas de diferentes intencionalidades e dos distintos projetos dos que praticam a cidade.

Palavras-chave: Técnicas da ação; Uso corporativo do território; Movimentos de SemTeto; Vazios urbanos.

\section{TECHNICS OF ACTION: AROUND THE DIALETIC BETWEEN CORPORATIVE USE OF TERRITORY AND HOMELESS ACTIONS}

Abstract: This article aims to discuss how, nowadays, the city create a selective and corporative use of the territory (SANTOS, 2005) by land and real estate markets that

${ }^{1}$ Geógrafo e mestre em Arquitetura e Urbanismo pela Universidade Federal de Alagoas. Contato: geocadu@gmail.com. 
produce artificially housing deficit through the income and speculative use of the urbanvoids which are potentially useful for a housing policy. At the same time, we intend to demonstrate how this process contributes to the emergency of homeless movements that occupy subversively urban voids, through programmed occupations, whose goal is to restore rights and break with the logic of private appropriation of the city by great capital. Our main aim is to point arguments for the necessary contextualization of distinct but complementary territorial practices that would affect the right to housing and how they would reinforce the corporative use of territory. Finally, we conclude that homeless actions, as contra-hegemonic actions (SANTOS, 2008a), result of the corporative use of territory by capital. Thus, the built environment is base for conflict operations resultant from different intentionality and distinct projects inside the city.

Keywords: Technics of action; Corporative use ofterritory; Homeless movement; Urban voids.

\section{Introdução}

Nos últimos anos, verifica-se, nas cidades brasileiras, um aumento expressivo no número de organizações de movimentos de sem-teto que, na luta pelo reconhecimento e efetivação do direito à moradia, engendram ações de ocupação de terras e equipamentos urbanos vazios localizados em áreas centrais e periféricas das cidades. Essas ações ocorrem em um contexto de acirramento das desigualdades geográficas marcadas por um uso seletivo e corporativo do território intraurbano (SANTOS, 2005) ensejado pelas forças do mercado e dos capitais fundiário, imobiliário e especulativo.

Este uso seletivo e corporativo da cidade pauta-se sobretudo nas práticas da gestão pública e dos agentes imobiliários que, regidos pela lógica econômica de acumulação de capital, se utilizam de normas que instituem uma verdadeira racionalização do espaço através da produção e distribuição de materialidades e funções urbanas que comumente se voltam contra os interesses sociais, dentre eles, o interesse e a possibilidade de se morar dignamente.

O consumo habitacional, nesse sentido, torna-se seletivo e atende a uma parcela da população. Outra parcela institui práticas comumente relacionadas pelos agentes econômicos à irracionalidade como, por exemplo, as ocupações planejadas de terras e prédios que servem como estoque de mercado. Tais ocupações denunciam, a priori, como a atual 
racionalização do território (SANTOS, 2008a) - calcada nas leis de mercado - pode tornar-se inapropriada ao bem-estar coletivo.

O meio construído, isto é, a base técnica, material e normativa do território se apresenta nos dias atuais como um regulador dos distintos interesses hegemônicos e não hegemônicos. Em outros termos, o meio construído orienta tanto as práticas do mercado e da política imobiliários, como as práticas dos que não participam ou se beneficiam desse mercado e dessa política ou que participam precariamente. Um terreno desocupado, um prédio vazio, a depender da localização no sítio urbano, pode servir tanto a operações especulativas do mercado como à revolta de sujeitos desprovidos de um teto em uma localização adequada.

As ações dos sem-teto devem ser contextualizadas a partir das contradições existentes no meio construído oriundas de dois processos distintos: (i) o primeiro que, comandado pelas finanças, busca uma apropriação de determinadas áreas da cidade para expansão do capital e extração de mais-valia fundiária; (ii) o segundo, à revelia do primeiro, busca instituir na cidade um novo padrão de produção, distribuição e consumo habitacional, calcado nos interesses e direitos sociais. É nesse contexto que entendemos que o meio construído se torna um importante elemento explicativo dos atuais conflitos urbanos em torno da moradia, ao tempo em que permite compreender o sentido real das ações dos sem-teto.

Resta saber como são gestados e acionados os dispositivos que instituem na cidade uma situação desigual e contraditória entre oferta e déficit habitacional, ou mesmo, entre poder permanecer em uma dada área ou ter que se deslocar em função das políticas de modernização e valorização fundiária e imobiliária.

Quais seriam os mecanismos que acionados ensejariam uma situação de déficit habitacional, ou seja, de permanente expropriação do direito à materialidade necessária à moradia digna? Como esses mecanismos, que funcionalizam o território usado (SANTOS e SILVEIRA, 2005), favorecem uns e punem outros no que se refere ao acesso à moradia?

$\mathrm{O}$ entendimento dos processos subjacentes às questões não é de fácil apreensão, mas talvez seja possível fazề-lo através do reconhecimento de determinadas práticas espaciais engendradas por distintos agentes e que nos permitiriam compreender as ações dos movimentos de sem-teto em um contexto no qual o território usado (SANTOS e SILVEIRA, 2005), ou o meio construído, se impõe como condição à realização de práticas e projetos contraditórios. Conforme Ribeiro, Barreto, et al. (2001, p. 37), o 
território usado “(...) constitui uma segura orientação analítica para leituras do espaço que reconheçam a centralidade das práticas na configuração de projetos políticos alternativos ao agir hegemônico". Nesse sentido destacamos, de modo geral, três práticas as quais entendemos úteis à compreensão da instauração da situação de carência habitacional e da supressão do direito à moradia.

A primeira prática diz respeito à natureza da política urbana. Atualmente, assiste-se a uma substituição da política urbana pela política da empresa, isto é, a subversão da ética social pela ética empresarial. É nesse sentido que Santos $(1998,2008 b)$ fala de uma política das empresas em detrimento da política dos Estados. Comumente, as gestões públicas das três esferas de governo preparam o território e destinam recursos públicos às ações do mercado imobiliário e dos agentes hegemônicos cujos interesses econômicos pautam-se num uso corporativo da cidade a serviço do lucro. Assim a gestão pública, através do planejamento urbano, racionalizaria o espaço segundo os interesses e direitos individuais, negando, constantemente, os interesses e direitos coletivos.

A segunda prática corresponderia à apropriação e manutenção, por agentes públicos e privados, de terrenos e prédios desocupados em áreas centrais da cidade, o que acaba por reproduzir artificialmente a "escassez" de terra e habitação e, por conseguinte, favorecer a especulação imobiliária ao tempo em que nega à população pobre o direito de acesso e uso dos vazios urbanos ${ }^{2}$ como objetos potencialmente úteis a uma política habitacional de interesse social.

A terceira prática consistiria no acionamento de leis e normas que privilegiariam o uso privado e desigual da cidade em detrimento do uso coletivo igualitário no qual seja salvaguardado o direito à moradia e aos demais atributos espaciais.

2 Borde (2003, p. 4 apud SANTANA, 2006, p. 32) define vazios urbanos como "terrenos localizados em áreas providas de infraestrutura que não realizam plenamente a sua função social e econômica". Clichevsky (2002, p. 8 apud SANTANA, 2006, p. 32) define vazios urbanos como "vazios especulativos, vazios latentes ou potenciais". É preciso considerar, ainda, conforme Santana (2006, p. 14), que "vazios urbanos não são apenas terrenos que se encontram vazios, sem uso, mas também estruturas edificadas vazias, ociosas e/ou subutilizadas". 


\section{O uso corporativo do território como condicionante das ações dos movimentos de ocupação de vazios urbanos}

O meio construído urbano admite, mediante um conjunto de materialidades, a existência de terrenos e prédios vazios potencialmente úteis à habitação. Estes vazios urbanos ganham significado à medida que deixam de ser considerados como objetos espaciais em si e são encarados como objetos espaciais instituídos de valor social, econômico e locacional.

Mas o valor desses objetos se dá segundo as intencionalidades e os usos que sobre eles recaem. Neste sentido, os vazios urbanos - segundo as distintas intencionalidades referentes ao uso - não possuem o mesmo valor social e econômico. Para um especulador imobiliário que detêm a posse da terra ou do imóvel, o vazio, como objeto geográfico, lhe representa e lhe é útil à obtenção de renda e de lucro. A um sem-teto, o mesmo vazio representa a possibilidade de utilizá-lo para suprir sua carência de moradia.

Portanto, a cidade é composta por um conjunto heterogêneo de intencionalidades que atribuem valores distintos aos mesmos objetos dispostos espacialmente. No período atual as intencionalidades são racionalmente forjadas através de normas e ações que buscam, a partir da materialidade construída, regular e controlar os usos do território para servir às atividades capitalistas. $\mathrm{O}$ próprio território se impõe, através da materialidade, como um condicionante tanto das operações de especulação do mercado quanto das ações contra-hegemônicas por parte daqueles que sofrem com tais regulações e constrangimentos referentes ao acesso e uso de áreas e prédios potencialmente úteis à moradia. A situação de carência, também materialmente existente no território, enseja ações contestatórias e subversivas à racionalidade hegemônica.

Mas como se aciona um conjunto de normas para privar os sujeitos de morar? E como essas normas criam uma situação de carência e restrição à materialidade necessária à moradia digna ao tempo em que fomentam, dialeticamente, o uso corporativo, seletivo e especulativo da terra e dos imóveis urbanos?

As cidades, nesse contexto, veem escapar o controle e a regulação locais da política habitacional ao responderem aos comandos externos, calcados na ética do mercado, que emanam do chamado mercado global. Assim, as cidades passam a responder aos comandos externos das grandes empresas ou dos modelos por elas criados, ensejando o uso corporativo do território para salvaguardar a forma capitalista de dominação seguida de expropriação. 
Esta forma capitalista de atividade se utiliza de instrumentos jurídicos que servem ao controle do uso e ocupação do solo já que são capazes de permitir ou restringir o acesso a determinadas áreas e equipamentos habitacionais. Nesse sentido, um conjunto de práticas e normas é racionalmente levado a cabo para criar, por um lado, uma situação favorável à carência habitacional e, consequente, especulação imobiliária e, por outro, restringir o acesso dos sem-teto à moradia tornando, assim, permanente a situação de carência. É importante lembrar que a forma de apropriação capitalista da terra urbana objetiva em muitos casos é a especulação através da extração da mais-valia e da renda fundiárias obtidas pelo trabalho ${ }^{3}$.

Ao partir de outra lógica circunstancial, os movimentos de ocupação de vazios urbanos se apropriam e usam os distintos espaços da cidade, inclusive propriedades públicas e privadas. As ações de ocupação expõem a contradição entre a existência efetiva de vazios urbanos que servem à especulação - mas são potencialmente úteis à moradia - e a não possibilidade de utilizá-los para moradia, sob o risco de romper com a lógica da demanda criada artificialmente e que comprometeria à especulação.

Nesse sentido, podemos dizer que as práticas do mercado são legitimadas a partir do que Foucault (1979, p. 13) chamou de "economia política da verdade" centrada "na forma do discurso científico e nas instituições que a produzem e que é transmitida sob o controle dos grandes aparelhos políticos ou econômicos" e que serviria, portanto, para tornar normal e socialmente aceita a existência de vazios urbanos tornados objetos especulativos e não objetos úteis à resolução do problema habitacional ${ }^{4}$.

\footnotetext{
3 “As mais-valias fundiárias (...) cabem ao conjunto da população que suporta os encargos relativos ao desenvolvimento e ao funcionamento da cidade. Entretanto, na ausência de uma ação positiva por parte do poder público, esses acréscimos de valor são apropriados de forma privada pelos proprietários dos terrenos beneficiados. (...)" (FURTADO, 2007, p. 345).

4 Para Foucault (1979, p. 14) “o problema não é mudar a 'consciência' das pessoas, ou o que elas têm na cabeça, mas o regime político, econômico, institucional de produção da verdade. Em suma, a questão política não é o erro, a ilusão, a consciência alienada ou a ideologia; é a própria verdade" (aspas no original).
} 
Dessa forma, o planejamento urbano fundamentado nessa "economia política da verdade" é pensado a partir do "estatuto daqueles que têm o encargo de dizer o que funciona como verdadeiro" (FOUCAULT, 1979, p. 13), de modo que as permissões e restrições quanto ao uso do solo urbano partem dos agentes econômicos que acabam por dominar, pelos objetos e pelas ações, a cidade infraestruturada, equipada e servida. Para Lojkini (1981, p. 54):

A planificação urbana não é mais o produto de um código de
urbanismo, mas sim o resultado de acordos mais ou menos
explícitos estabelecidos entre os dirigentes do aparelho do
Estado, alguns interesses econômicos e financeiros e um
punhado de políticos locais... O Estado seleciona alguns
grupos econômicos e sociais que transformam em parceiros
privilegiados e com os quais exerce arbitragens.

Nessa perspectiva, Cataia (2001, p. 152) propõe o conceito de território alienado para designar "aqueles municípios que prepararam o seu chão com obras de engenharia e normas, receberam investimentos empresariais e tornaram-se reféns das políticas empresariais".

Ao alienar o território a interesses privados; ao sujeitar a terra e a habitação às leis do mercado; ao privatizar os interesses e investimentos públicos; uma cidade cindida e fragmentada surge como corolário desses processos. E é essa cidade fragmentada que passa a orientar, cada vez mais, tanto as ações dos especuladores como as ações insurgentes dos sem-teto, num incessante movimento dialético no qual operam forças antagônicas que passam a reconfigurar o meio construído.

A seletividade do mercado implica na seletividade do território com sua gente e, portanto, na seletividade da produção e destinação de materialidades necessárias à moradia digna: sistemas de abastecimento de água, luz, transporte, oferta de emprego etc. Contudo, parte desta infraestrutura existe em áreas potencialmente úteis à moradia, mas que têm o seu uso habitacional subestimado e, para além desse fator, nega o acesso àqueles que não possuem condições rentáveis para adquirir os serviços.

Portanto, a gestão pública como detentora da capacidade legítima e legal de redistribuir tais serviços e realizar uma adequada política habitacional - sem considerar os fatores financeiros que comumente constrangem as ações públicas - se nega muitas vezes em fazê-lo, pois, mesmo diante de uma suposta capacidade financeira é preciso reforçar que 
o financiamento destinado à produção e distribuição de materialidades é ofertado a determinados setores econômicos e, por conseguinte, a determinados fragmentos da cidade.

É nesse contexto que explodem na cena urbana uma multiplicidade de protestos e reivindicações por parte dos movimentos organizados de sem-teto e de outros segmentos sociais no tocante aos investimentos e beneficiamento de determinadas áreas da cidade em detrimento de outras. Constituem-se outras racionalidades alternativas à racionalidade hegemônica. Estas outras racionalidades que orientam as práticas dos "sem" instituem novas formas, normas e maneiras de se pensar e se praticar a cidade ao abrir espaço à diversidade de atores e interesses.

A fim de compreender essas outras racionalidades, que partem dos homens lentos (SANTOS, 2008b), é preciso confrontá-las com aquelas que estão postas e que dominam a cidade por meio das três práticas que fomentam uma situação contraditória entre riqueza e pobreza e entre abundância e escassez.

A primeira prática se refere às ações planejadas do poder público e que são voltadas aos interesses privados; a segunda aponta para as formas de utilização dos vazios urbanos pelo mercado e que objetivam fomentar a especulação e (re)produção de déficit habitacional através da produção artificial da escassez de terra e habitação; e a terceira prática corresponde aos instrumentos normativos por meio dos quais as instituições jurídicas e executivas operam e aplicam o direito à propriedade (individual) em detrimento do direito à moradia (público/coletivo).

Propomos a averiguação de tais práticas para se compreender as formas de dominação e racionalização do espaço pelo Estado e pelo mercado, isto é, pelas instituições públicas e pelos agentes econômicos imobiliários que ao instrumentalizarem o território através de normas e criarem as condições para o seu uso acabam por instaurar contradições e pressionar as ações dos movimentos organizados de sem-teto. 


\section{Da política urbana à política dos setores imobiliários ${ }^{5}$}

Na cidade, não raro, o mercado imobiliário e as empresas orientam a criação de normas urbanísticas que favoreçam o próprio poder econômico no que se refere às ações do poder público. Conforme Ribeiro (2004, p. 349), os vínculos entre poder econômico e poder administrativo têm caracterizado as gestões públicas atuais que "sem maiores investimentos discursivos e descartando a política" contribuem para a anulação da participação da população nos debates e na elaboração das políticas públicas.

Nesse sentido, o planejamento empresarial toma o lugar do "planejamento como fato político aberto às disputas de poder" (RIBEIRO, 2008). Ao ceder lugar à gestão há um "aprofundamento da desigualdade na disputa de oportunidades, já que esta é reduzida ao 'universo imediato da ação' no qual quem dispõe de condições materiais e imateriais para uma 'veloz definição de projetos' é o vitorioso" (RIBEIRO, 2014).

Dessa forma, os setores imobiliários acabam por delinear a política habitacional brasileira de modo que o Estado age no sentido de facilitar o uso do território urbano pelo mercado em áreas que oferecem maior dinamismo e valorização às atividades mais capitalizadas.

A gestão pública age seletivamente, pontualmente e deficientemente para suprir as necessidades habitacionais da parcela que fica fora do mercado imobiliário, pois este atende prioritariamente a população economicamente privilegiada "marcando o uso corporativo do território" (MIRANDA, 2005, p. 100). Seriam basicamente duas políticas habitacionais distintas para classes distintas que, incapazes de universalizar o direito à moradia, reafirmam a desigualdade. Vale a observação de Santos (2008b, p. 67) que diz:

A política, por definição, é sempre ampla e supõe uma visão
de conjunto. Ela apenas se realiza quando existe a
consideração de todos e de tudo. Quem não tem visão de
conjunto não chega a ser político. E não há política apenas
para os pobres, como não há apenas para os ricos. A

${ }^{5}$ Este subtítulo faz alusão ao artigo de SANTOS (1998) intitulado Da Política dos Estados à Política das Empresas.

6 "Transformar-se para estar presente na captura de investimentos tem se tornado, pelo menos aparentemente, mais relevante do que dispor de regras para a interação social" (RIBEIRO e SILVA, 2004, p. 355). 
eliminação da pobreza é um problema estrutural. Fora daí o que se pretende é encontrar formas de proteção a certos pobres e a certos ricos, escolhidos segundo os interesses dos doadores. Mas a política tem de cuidar do conjunto de realidades e do conjunto de relações.

Contrários a esta noção de política, tomamos como exemplo $o$ zoneamento que, como instrumento de planejamento, define as áreas a serem ocupadas pelo mercado imobiliário para média e alta renda e que negligencia as áreas ocupadas pela população de baixa renda. O zoneamento acaba por ser posto "a serviço da segregação e da especulação" (SANTOS, 2003, p. 198). Esse planejamento setorial, "por ser aderente aos interesses dos agentes hegemônicos, pretensamente apolítico, neutro e técnico encobre as perversidades feitas através dos acordos entre Estado e interesses privados" (MELGAÇO, 2005, p. 77).

De acordo com Melgaço (2005, p. 76) o planejamento se divide em duas grandes escolas: a analítica e a dialética. Segundo ele "a escola analítica vê o planejamento como um conjunto de técnicas e procedimentos" enquanto que a dialética encara o planejamento "como uma questão não apenas técnica, mas também política" possibilitando o "embate de interesses". No Brasil, a prática de planejamento urbano se utiliza do método analítico, logo, recorta o território setorialmente de modo que cada grupo econômico age de acordo com seus interesses.

A cidade passa a ser organizada por "operações especulativas e classificatórias" sob as quais a "gestão combina-se com a eliminação" (CERTEAU, 1994, p. 173). Nesta resistência à eliminação espacial, os sem-teto ou os que moram precariamente atuam subversivamente na cidade e contrariam a ordem hegemônica estabelecida, respaldados na máxima "enquanto morar for um privilégio, ocupar é um direito" (UNIÃO NACIONAL POR MORADIA POPULAR, 2008, grifos do autor).

Desse modo, concordamos com Melgaço (2005, p. 77) quando diz que "o planejamento territorial deve levar em conta os interesses dos lugares, e não apenas interesses externos a estes", pois, como afirma Certeau “(...) planejar a cidade é ao mesmo tempo pensar a própria pluralidade do real e dar efetividade a este pensamento do plural: é saber e poder articular" (1994, p. 172).

O planejamento deve "pensar a pluralidade e indissociabilidade entre materialidade e ação, entre técnica e política" (MELGAÇO, p. 77) abrindose espaço para que "os acordos não sejam incentivados apenas entre alguns 
poucos agentes hegemônicos, e sim entre todos os agentes, inclusive os hegemonizados" (p. 89).

Assim, podemos vislumbrar como possibilidade o uso de vazios urbanos pelos sem-teto a partir das ocupações de tais vazios que contrariam e questionam as desarticulações sociais pretendidas e levadas a cabo pela racionalidade econômica. Nesse sentido, o planejamento deve fazer nexo com o desejo, com a base cultural, pensado não só pelos técnicos, mas pelos praticantes de espaço, como reivindica Ribeiro (2008).

\section{A produção artificial da escassez habitacional}

Frequentemente, técnicos de governo, gestores públicos e agentes imobiliários entendem o déficit habitacional como a "necessidade de construção de novas moradias para solução de problemas sociais e específicos de habitação ${ }^{7 "}$ e resistem em debater acerca das causas macroestruturais desse problema territorialmente consolidado.

Por isso, sugerimos a compreensão do déficit habitacional no contexto desta urbanização corporativa definida por Santos (2005, p. 105) como aquela "empreendida sob o comando dos interesses das grandes firmas" que ignoram as demandas e interesses de parcela da cidade.

Azevedo (1988 apud FUNDAÇÃO JOÃO PINHEIRO, 2005, p. 76) ${ }^{8}$ constatou que a política habitacional no período do Banco Nacional de Habitação (1964-1986) "privilegiou a classe média e os setores de maior renda" visto que "cerca de $70 \%$ das unidades construídas nos 22 anos de existência do BNH foram destinados às famílias com renda mensal acima de cinco salários mínimos". O autor diz que:

${ }^{7}$ Esta é uma das noções de déficit habitacional trabalhada pela Fundação João Pinheiro (2005, p. 7). Chamamos a atenção para o fato de que é esta noção que orienta grande parte das políticas públicas habitacionais. Entendemos que a consideração da questão do déficit habitacional como um problema a ser resolvido unicamente através da construção de mais unidades habitacionais dificulta a compreensão mais ampla do problema e o necessário enfrentamento e restauração do direito à moradia a partir do debate em torno dos possíveis projetos e usos distintos do território pela habitação.

8 AZEVEDO, Sergio. Vinte e dois anos de política de habitação popular (1964-1986): criação, trajetória e extinção do BNH. Revista de Administração Pública, Rio de Janeiro, v. 22, n. 4, out./dez. 1988. pp. 107-119. 
A clientela inicialmente definida como o núcleo central da política - famílias com renda até três salários mínimos terminou por ser praticamente descartada do centro de atenção do banco (AZEVEDO, 1990 apud FUNDAÇÃO JOÃO PINHEIRO, 2005, p. 76) ${ }^{9}$.

Os recursos públicos foram direcionados aos segmentos sociais de mais alta renda, beneficiando uma parcela e deixando outra à margem da política empreendida na época. Em termos geográficos isso significou investimento em determinados bairros da cidade em detrimento de outros; mas também um espraiamento urbano induzindo um processo de valorização diferenciada das frações da cidade segundo a maior ou menor densidade técnica. Segundo Santos (2008a, p. 306):

Os objetos técnicos de alguma forma são o fundamento dos valores de uso e dos valores de troca dos diversos pedaços da cidade. Pode-se dizer que, consideradas em sua realidade técnica e em seus regulamentos de uso, as infraestruturas "regulam" comportamentos e desse modo "escolhem", "selecionam" os atores possíveis. Certos espaços da produção, da circulação e do consumo são a área de exercício dos atores "racionais", enquanto os demais atores se contentam com as frações urbanas menos equipadas. A ação humana é desse modo compartimentada segundo níveis de racionalidade da matéria (aspas no original).

É nesse sentido que Villaça (1998, p. 174) diz que “a terra urbana só interessa enquanto 'terra-localização', ou seja, enquanto meio de acesso a todo o sistema urbano, a toda a cidade" de modo que "a acessibilidade é o valor de uso mais importante para a terra urbana" (grifos do original). Tal acessibilidade está relacionada à presença de infraestruturas, equipamentos, serviços etc. No entanto nem todas as áreas são usadas da mesma forma, de modo que algumas permanecem vazias. Esta é uma característica da urbanização brasileira em que "setores econômicos se apropriam de vastas áreas entremeadas de vazios caracterizando o uso corporativo do território" (SANTOS, 2005a, p. 106).

${ }^{9}$ AZEVEDO, Sergio de. A trajetória dos programas alternativos de habitação popular no Brasil. Revista de Administração Municipal, Rio de Janeiro, v. 37, n. 195, abr./jun. 1990. pp. 6-25 
Os vazios urbanos considerados a partir do trinômio terralocalização-acessibilidade encontram seu valor de uso condicionado ao valor de troca. Para isso o solo das áreas infraestruturadas e equipadas passa a ser regulado por instrumentos jurídicos que garantem o domínio, a fim de torná-lo produto que só pode ser acessado através da compra. Aqueles que não têm garantida uma renda mínima para acessar tais áreas moram nas partes escassas da cidade, portanto, mais baratas ou sem valor de mercado.

O déficit, nesse sentido, não é só de unidades habitacionais, mas de infraestrutura, equipamentos, serviços, lazer, etc. Este déficit coexiste com extensas áreas vazias dentro da cidade que poderiam ter seus usos otimizados no sentido de aproveitamento da materialidade construída. Todavia, a impossibilidade desse uso reside apenas nos marcos da racionalidade hegemônica que resiste em considerar possibilidades que não coincidam com o interesse do mercado que, neste caso, usa os vazios como objetos rentáveis e passíveis de especulação ${ }^{10}$. Por isso, para especular é preciso forjar uma situação de vacância fundiária e habitacional a fim de criar artificialmente uma situação de escassez. É nesse sentido que o déficit habitacional e os vazios urbanos resultam de um mesmo movimento contraditório fundamental ao mercado ${ }^{11}$.

Santos (2005, p. 106) explica este movimento contraditório entre carência habitacional e especulação: "havendo especulação, há criação mercantil da escassez e acentua-se o problema do acesso à terra e à habitação. Mas o déficit de residências também leva à especulação, e os dois juntos conduzem à periferização da população mais pobre (...)"

Portanto o vazio urbano constitui um objeto geográfico fundamental ao funcionamento e operação combinada entre mercado imobiliário e mercado financeiro mediante a possibilidade de especulação e extração de renda. O vazio urbano - como objeto de especulação e como terra-

10 Borde afirma que “(...) manter uma situação de vacância urbana em área valorizada passa a ser tão ou mais rentável, do ponto de vista do mercado de terra urbanas, quanto ocupá-la ou reutilizá-la. Com a valorização do solo urbano, as situações de vazio urbano passam a ser produzidas, reproduzidas e mantidas. Elas passam a ser orientadas pela lógica de retenção especulativa do solo urbano" (2006, p. 11).

${ }^{11}$ Em meados de 2008 "o déficit habitacional em áreas urbanas foi recentemente estimado em 7,2 milhões de unidades no país, sendo que o número de imóveis vazios nessas áreas foi calculado em cerca de cinco milhões de unidades" (FERNANDES, 2008c, p. 64). 
localização-acessibilidade - pode ser considerado um objeto já que possui uma forma de intencionalidade que, juntamente com os demais atributos espaciais, condiciona as formas de ação e se presta a uma finalidade última, qual seja, a especulação. Santos (2003, p. 190) nos diz que "a propriedade da terra é, ela própria, uma forma: uma forma jurídica, mas também espacial" e como forma "comporta uma finalidade a ser cumprida".

Para Santos (2008a, p. 156) "um objeto tomado isoladamente tem um valor como coisa, mas o seu valor como dado social vem de sua existência relacional. (...) Essa valoração do objeto está ligada à maneira como a sociedade dele se utiliza". Se transferirmos esta premissa ao vazio urbano, nós compreenderemos que a sua valoração está relacionada à maneira como a sociedade se utiliza dele. Mas a sociedade não constitui um todo monolítico. Ela é formada por um conjunto de agentes com distintos interesses e capacidade de ação. Nesse sentido é preciso levar em consideração, para se compreender a valoração atribuída aos objetos geográficos, os diferentes agentes que participam da produção do espaço urbano, como sugere Corrêa (1989): os proprietários fundiários, os promotores imobiliários, o Estado, os grupos sociais excluídos.

Ao considerarmos o papel de cada um destes agentes, podemos compreender como cada um deles se utiliza potencial ou efetivamente de um mesmo vazio urbano a partir de intencionalidades distintas: os promotores imobiliários utilizam o vazio urbano para especular; os movimentos de sem-teto, quando ocupam, subvertem esta finalidade e dão outra função ao que estava vazio. Para além da contrarresposta à especulação, os sem-teto ameaçam romper com a intencionalidade original, qual seja, a da utilização do vazio urbano como objeto útil à especulação e extração de renda fundiária em detrimento da necessidade e do direito à moradia.

\section{Villaça (1998, p. 45) argumenta que}

A força mais poderosa (mas não única) agindo sobre a estruturação do espaço intraurbano tem origem na luta de classes pela apropriação diferenciada das vantagens e desvantagens do espaço construído e na segregação espacial dela resultante.

Nesta luta engendrada pelos movimentos de sem-teto, que buscam também apropriar-se das vantagens do espaço, algumas conquistas e retrocessos ocorreram nos últimos anos. Como conquista podemos citar a 
Lei $n^{\circ} 10.257 / 2001$, autonomeada Estatuto da Cidade, que surgiu como um marco histórico no que se refere à criação de novos dispositivos normativos que pretendem combater o uso irracional e intencional do solo urbano para fins especulativos. Tal Lei traz em seu conteúdo instrumentos jurídicos e urbanísticos que se preocupam com o atendimento das demandas sociais e com a possibilidade de rompimento com este processo mantenedor do déficit habitacional ${ }^{12}$.

\section{Da contradição normativa à contradição territorial}

Entendemos que o combate ao déficit habitacional deve se seguir concomitantemente do combate aos instrumentos que favorecem a especulação, dentre eles os próprios vazios urbanos. Não é possível combater o déficit apenas com a construção de unidades habitacionais em áreas periféricas ou mesmo garantir o direito à moradia mantendo as mesmas práticas territoriais no que concerne às ações do poder público e do mercado imobiliário.

Dessa forma, o rompimento com a especulação através do uso habitacional dos vazios urbanos em áreas infraestruturadas possibilitaria uma melhor distribuição dos benefícios materiais e imateriais da cidade. Este princípio coaduna-se com o direito à moradia - como um direito mais amplo e social - e contraria, em certa medida, o direito à propriedade como direito restrito, visto que este último propicia as práticas dominantes existentes pelas quais os proprietários encontram as condições para deixar permanecerem vazias as suas propriedades a fim de aumentar o preço da terra, dos imóveis e dos aluguéis.

É possível entender a contradição e o conflito entre direito de propriedade e o direito à moradia em termos jurídicos. Mas em termos geográficos, cujas práticas cotidianas violam constantemente ambos os direitos, a explicação deve partir da contradição das ações e dos objetos materializados territorialmente.

\footnotetext{
12 Mencionamos, ainda, como avanço jurídico-institucional para reconhecimento do direito à moradia e combate à especulação imobiliária, a Lei no 11.124 , de 16 de junho de 2005, que dispõe sobre o Sistema Nacional de Habitação de Interesse Social (SNHIS), cria o Fundo Nacional de Habitação de Interesse Social (FNHIS) e institui o Conselho Gestor do FNHIS.
} 
Quando o Estado e as empresas se apropriam de vastas áreas e selecionam a população a ser atendida pelas políticas públicas urbanas e pelo mercado, negando as mesmas oportunidades e condições a toda cidade, há uma violação do direito à moradia. Quando a parcela dos semteto ocupa vazios urbanos em áreas centrais e de interesse do mercado imobiliário há uma violação do direito de propriedade.

Em termos jurídicos, como afirmamos, a contradição dos direitos está no fato do reconhecimento, coisa que Souza Filho explica ser "ideia de propriedade privada (...) um bem, uma coisa (...) significa que ele é individual, físico, concreto" (1999, p. 309). Nesta lógica só pode ser o "direito coletivo o conjunto ou a soma dos direitos individuais, e como direitos individuais, tratados" (p. 311). Na mesma perspectiva, para Lins (2008, p. 237) se não "há 'coisas', ou seja, 'soma de patrimônios individuais', a função social da propriedade corre o risco de não ser tratada pelo sistema dominante $\mathrm{e}$, por conseguinte, o direito à moradia" (aspas no original). Para ele,

Enquanto uns lutam pelo direito à moradia, direito humano básico e, em última instância, direito à vida - coletivos e difusos, os outros brigam pelo direito à propriedade individual e objetivo, o direito à coisa. Este último é portador de visibilidade plena nos sistemas dominantes, enquanto aquele outro é absolutamente invisível (2008, p. 237).

No entanto, conforme Fernandes (2008b, p. 46)

(...) o direito de propriedade imobiliária urbana [deveria ser somente] assegurado desde que cumprida sua função social, que por sua vez é aquela determinada pela legislação urbanística, sobretudo no contexto municipal.

O problema é que, ainda de acordo com o mesmo autor (2008a, p. 24), a Constituição de 1988 não diz quando e como ocorre esta função social da propriedade, outorgando ao município dizê-lo através do Plano Diretor $^{13}$. O fato é que em muitos municípios brasileiros a propriedade privada não está condicionada a nenhuma função social já que esta não é

${ }^{13} \mathrm{O} \S 2^{\circ}$ do artigo 182 da Constituição Federativa do Brasil de 1988 dispõe que "a propriedade urbana cumpre sua função social quando atende às exigências fundamentais de ordenação da cidade expressas no Plano Diretor". 
definida no Plano Diretor do município ou em qualquer outra legislação urbanística, permitindo a permanência de vazios voltados à especulação.

De acordo com Fernandes (2003, p. 64), para que o direito à moradia fosse materializado como direito coletivo e difuso, seria preciso "separar o tratamento jurídico do direito de propriedade imobiliária do âmbito individualista do Direito Civil para colocá-lo no âmbito social do Direito Urbanístico". Ainda segundo o autor "é necessário separar o tratamento jurídico da gestão urbana do âmbito restrito do Direito Administrativo para colocá-lo no âmbito mais amplo do Direito Urbanístico". Isso requer, conforme o autor, uma mudança de paradigma na maneira como se reflete o direito urbanístico e a gestão urbana.

A não apropriação dos instrumentos jurídicos e urbanísticos contidos no Estatuto da Cidade e a não incorporação destes instrumentos nas práticas da gestão urbana sugerem que o Direito Administrativo - em que a burocratização das ações impera, bem como os interesses das empresas - é preponderante, de modo que "o desenvolvimento urbano da cidade tem sido pautado pelo Direito de Propriedade Individual não restringido" (FERNANDES, 2003, p. 65).

Contudo, como nos afirma Derzi (1991, p. 177), "não existe direito de propriedade absoluto, porque não existem quaisquer direitos individuais absolutos". Segundo ele são três os dispositivos e princípios extraídos do próprio texto constitucional que restringem o direito de propriedade absoluto: a desapropriação, a função social da propriedade e o IPTU Progressivo ${ }^{14}$.

Isso denota que a atual "ordem jurídico-urbanística" referenciada nos mandamentos do mercado global - que propõe soluções descabidas para o uso corporativo do território e até o reforça - "não encontra respaldo na política institucional e administrativa" local (FERNANDES, 2008c, p. 68) ao negar esta última e utilizar velhos mecanismos do liberalismo jurídico clássico para garantir seu uso corporativo.

E mesmo aquelas gestões mais progressistas, que tentam engendrar ações mais democráticas e equalizadas do espaço urbano, encontram dificuldades para fazê-lo porque a ordem "jurídico-institucional não reflete a ordem urbano-territorial", isto é, não leva em conta a diversidade de

${ }^{14}$ Fernandes (2007, p. 144) acrescenta, ainda, o Estatuto da Cidade e o art. $6^{\circ}$ da Constituição Federal de 1988 que trata o direito à moradia como direito social. 
interesses e contradições dos que praticam o território (FERNANDES, 2008 c, p. 68$)^{15}$.

Concordamos com Fernandes quando ressalta

(...) o papel importante cumprido pelas leis elitistas e socialmente inadequadas que têm historicamente desconsiderado as realidades dos processos socioeconômicos de produção da moradia, exigindo padrões técnicos e urbanísticos inatingíveis, acabando por reservar as áreas nobres e providas de infraestrutura para o mercado imobiliário destinado às classes médias e altas, e ignorando assim as necessidades de moradia dos grupos menos favorecidos. Tal processo tem sido agravado pela falta de políticas urbanísticas e fiscais efetivas de combate à especulação imobiliária (2008b, p. 55).

Distantes desta ordem jurídico-urbanística, jurídico-institucional e político-institucional, os movimentos de sem-teto têm encontrado soluções para o atendimento de suas demandas utilizando o meio construído da cidade e redescobrindo suas possibilidades de uso. As ocupações dos vazios urbanos em áreas centrais e em áreas infraestruturadas se apresentam, a um só tempo, como protesto contra o uso corporativo do território e como solução possível para a falta de acesso à moradia.

Caberia à gestão urbana, que não pode ser dissociada desta nova ordem jurídico-urbanística (FERNANDES, 2008c, p. 69), reconhecer as ocupações de sem-teto como práticas factíveis na cidade e que possuem seu sentido e sua raison d'être ${ }^{16}$.

Para Ribeiro apud (MIRANDA 2005, p. 105) "negar estas práticas espaciais é negar o outro em sua capacidade propositiva" ocorrendo constantemente uma "criminalização deste outro [na perspectiva de que este] com suas ações e seus valores não é adequado à ordem dominante".

\footnotetext{
15 "A verdade é que, por várias razões, a ordem jurídico-política constitucional não expressa a ordem político-social construída no cotidiano dos processos políticos do país" (FERNANDES, 2008b, p. 51).

${ }^{16}$ Como atesta Antas Jr., com as devidas ressalvas, é claro, "o Estado perdeu o monopólio da produção de normas e a noção de soberania, (...) sendo a noção de pluralismo jurídico fundamental para a compreensão dos vários sistemas e subsistemas de ações, em copresença nos lugares" (2004, p. 81).
} 
Diante disso Santos (2008b, p. 120) diz que essa proliferação de "ilegais", "irregulares" e "informais" se dá porque "boa parcela da humanidade, por desinteresse ou incapacidade, não é mais capaz de obedecer a leis, normas, regras, mandamentos, costumes derivados dessa racionalidade hegemônica".

A questão do reconhecimento vem à tona novamente. Como dito anteriormente, a compreensão da contradição jurídica materializada no espaço deve ser buscada no reconhecimento não só da lei, mas da realidade. $\mathrm{O}$ direito à moradia é reconhecido juridicamente, mas o seu reconhecimento jurídico não encontra respaldo na realidade socioterritorial concreta $^{17}$.

Um primeiro passo no sentido do reconhecimento do direito à moradia seria "o de recusar a noção de informalidade" na análise das experiências de ocupações urbanas, "já que essa é uma categoria que simplifica a complexidade dessas territorialidades - 'a não-forma' - e, com isso, impede a apreensão real dessas experiências" (RIBEIRO, 2005 apud MIRANDA, 2005, p. 104, aspas no original).

Nesse sentido, como propõe Ribeiro (2005 apud MIRANDA, 2005, p. 104), o que deve ser posto em debate é a "produção social da ilegalidade" reconhecendo "o processo instituinte dos direitos, as articulações que o envolve e a reflexão sobre qual a legalidade possível e a partir de que projeto de futuro ela é desenhada ${ }^{18}$.

\footnotetext{
${ }^{17}$ Segundo Pallamin "foram caracterizadas três formas básicas de reconhecimento: o amor, associado à família, tomada como o lugar da relação afetiva do reconhecimento; o direito, associado à sociedade civil, lugar da relação cognitivo-formal em que o indivíduo é reconhecido como 'pessoa de direito'; e a solidariedade, reportando-se ao Estado enquanto lugar em que se realiza a autoestima social" (2005, p. 57). Entretanto é importante destacar, segundo a autora, que "as esferas de reconhecimento jurídico e familiar não garantem a ocorrência do reconhecimento social, da solidariedade. O tema do racismo exemplifica a questão, pois uma lei impedindo a discriminação não assegura que esta não ocorra efetivamente" (p. 59).

${ }^{18}$ Felix (2002, p. 8) "lembra que existem leis criadas para atender ao interesse de classes específicas". Por isso, para Melgaço (2005, p. 19) “a legalidade, portanto, não pode ser o ponto de partida para as discussões sobre a justiça urbana".
} 


\section{Considerações Finais}

Os movimentos de sem-teto que ocupam vazios urbanos surgem como questionadores de uma produção social da ilegalidade denunciada pelos mesmos agentes hegemônicos que são incapazes de garantir-lhes direitos. Estes movimentos se utilizam "do direito negado" para "passar da situação de carência à reivindicação" (JACOBI, 1993, p. 151). "No campo e nas cidades o aprendizado e a crítica da racionalidade hegemônica se fazem através do uso da técnica e da experiência da escassez" (SANTOS, 2008a, p. 307).

A falta de uma ação planejada que considere os diferentes agentes e interesses; as práticas da gestão pública que se voltam ao atendimento dos interesses privados; a utilização de vazios urbanos para fins especulativos produtores de déficit habitacional; a valorização do direito de propriedade (individual) em detrimento do direito à moradia (coletivo); a proliferação de normas para garantir o eficaz funcionamento da cidade para o atendimento das atividades capitalistas $^{19}$; todos estes processos territorialmente consolidados apontam para a perpetuação e aprofundamento dos conflitos urbanos.

Desse modo é preciso ir além das constatações e descrições das ações de ocupações de vazios urbanos pelos sem-teto devendo-se avançar na compreensão dos conflitos a partir do contexto em que se acirram as desigualdades territoriais. Em outros termos, é preciso captar os processos que geram na cidade contradições que emanam do embate de forças entre Estado, mercado e sociedade e que têm como elemento central para realização dos projetos conflitantes o próprio meio construído.

Portanto, torna-se fundamental contextualizar as ocupações de vazios urbanos pelos movimentos de sem-teto a partir das razões que incitam suas ações e vice-versa. A hegemonização das ações e do espaço contraria os diferentes modos de ser na cidade. As ocupações de vazios urbanos pelos movimentos de sem-teto evidenciam a emergência de outras racionalidades que precisam ser apreendidas a fim de se desvendar e explorar as possibilidades de uso mais justas e dignas na/da cidade.

\footnotetext{
19 "O fato de que a norma se tornou indispensável ao processo produtivo, conduz, ao mesmo tempo, à sua proliferação e leva, naturalmente, a um conflito de normas que o mercado não basta para resolver" (SANTOS, 2008a, p. 336).
} 


\section{Bibliografia}

ANTAS Jr., R. M. (2004) Elementos para uma discussão epistemológica sobre a regulação no território. Geousp - Espaço e Tempo, $\mathrm{n}^{\circ}$ 16. São Paulo. pp. 81-86.

BORDE, A. de L. P. (2006) Vazios Urbanos: perspectivas contemporâneas. Tese. (Doutorado em Urbanismo). Universidade Federal do Rio de Janeiro. Rio de Janeiro.

BRASIL. (2007) Constituição, 1988. Constituição da República Federativa do Brasil. Texto Constitucional de 1988. 28 ed. Brasília: Câmara dos Deputados, Coordenação de Publicações.

BRASIL. (2001) Estatuto da Cidade Lei $n^{\circ} 10.257$, de 10 de julho de 2001. Regulamenta os Arts. 182 e 183 da Constituição Federal de 1988, estabelece diretrizes gerais da política urbana e dá outras providências. Diário Oficial da União, 11 jul. 2001.

CATAIA, M. A. (2001). Território Nacional e Fronteiras Internas: A fragmentação do Território Brasileiro. Tese (Doutorado em Geografia Humana). Departamento de Geografia da Faculdade de Filosofia, Letras e Ciências Humanas da Universidade de São Paulo. São Paulo.

CERTEAU, M. de. (1994) A invenção do cotidiano: 1. Artes de fazer. Tradução de Ephraim Ferreira Alves. Petrópolis, RJ: Vozes.

CORRÊA, Roberto L. (1989). O Espaço urbano. 2 ed. Rio de Janeiro: Editora Ática, Série Princípios.

DERZI, M. A. M. (1998) Nota de atualização. In: BALEEIRO, A. (Org.). Limitações constitucionais ao poder de tributar. 7 ed. Rio de Janeiro: Forense.

FELIX, H. (1993) A Violência Urbana: ensaio. São Paulo: João Scortecci.

FERNANDES, C. E. (2007) O desenvolvimento dos municípios através da tributação imobiliária e do Estatuto da Cidade. In: CUNHA, E. M. P.; CESARE, C. M. de. (Orgs.). Financiamento das Cidades: instrumentos fiscais e de política urbana. Brasília: Ministério das Cidades.

FERNANDES, E. (2003) Del Código Civil al Estatuto de la Ciudad: algunas notas sobre la traycetoria del Derecho Urbanístico en Brasil. In: Revista Eure, vol. XXIX. Santiago de Chile. pp. 63-78.

(2008a) A palestra. In: VALENÇA, Márcio Moraes (Org.). Cidade (i)legal. Rio de Janeiro: Mauad X. 
(2008b) Do Código Civil ao Estatuto da Cidade: algumas notas sobre a trajetória do Direito Urbanístico no Brasil. In: VALENÇA, Márcio Moraes (Org.). Cidade (i)legal. Rio de Janeiro: Mauad X.

. (2008c) Reformando a ordem jurídico-urbanística no Brasil. In: VALENÇA, Márcio Moraes (Org.). Cidade (i)legal. Rio de Janeiro: Mauad X.

FOUCAULT, M. (1979) Microfísica do poder. Organização e Tradução de Roberto Machado. Rio de Janeiro: Edições Graal.

FUNDAÇÃO JOÃO PINHEIRO. (2005) Déficit habitacional no Brasil. 2. ed. Belo Horizonte.

FURTADO, F. (2007) Instrumentos para a gestão social da valorização da terra: fundamentação, caracterização e desafios. In: CUNHA, E. P. P.; CESARE, C. M. de (Orgs.). Financiamento das Cidades: instrumentos fiscais e de política urbana. Brasília: Ministério das Cidades.

JACOBI, P. Movimentos sociais e políticas públicas: demandas por saneamento básico e saúde. 2. ed. São Paulo: Cortez.

LINS, R. D. B. A (2008) Regularização fundiária como reconhecimento de direitos: os empreendimentos residenciais Vila Emater II e Vista Atlântica. In: VALENÇA, Márcio Moraes (Org.). Cidade (i)legal. Rio de Janeiro: Mauad X.

LOJKINE, J. (1981) O Estado Capitalista e a Questão Urbana. São Paulo: Martins Fontes.

MELGAÇO, L. de M. (2005) A Geografia do Atrito: dialética espacial e a violência em Campinas. 128 f. Dissertação (Mestrado em Geografia Humana). Departamento de Geografia da Faculdade de Filosofia, Letras e Ciências Humanas da Universidade de São Paulo. São Paulo.

MIRANDA, A. L. (2005) O Uso do Território pelos Homens Lentos: a experiência dos Camelôs no Centro de Ribeirão Preto. $141 \mathrm{f}$. Dissertação (Mestrado em Geografia). Instituto de Geociências. Universidade Estadual de Campinas. Campinas, SP.

RIBEIRO, A. C. T. (2008) Seminário de Planejamento e Política. Disponível em: http://www.coopere.net/ppla/downloads/AnexoEntrevista_Ana_Clara_Ribeiro.pdf. Acessado em: 16 ago. 2009. . (2014 [2002]). Teorias da ação. Rio de Janeiro: Letra Capital.

RIBEIRO, A. C. T.; BARRETO, A. R. S., et al. (2001) Por uma Cartografia da Ação: pequeno ensaio de método. Planejamento $e$ 
Território: ensaios sobre a desigualdade. Cadernos IPPUR, ano XV, n. 2. pp. 33-52.

RIBEIRO, A. C. T.; SILVA, C. A. da. (2004) Impulsos globais e espaço urbano: sobre o novo economicismo. Consejo Latinoamericano de Ciencias Sociales - CLACSO. Ciudad Autónoma de Buenos Aires.

SANTANA, L. S. (2006) Os vazios urbanos nos centros de cidades como lugar para habitação de interesse social: o caso de Maceió/AL. $155 \mathrm{f}$. Dissertação. (Mestrado em Arquitetura e Urbanismo). Faculdade de Arquitetura e Urbanismo, Maceió.

SANTOS, M. (1998) Da Política dos Estados à Política das Empresas. In: Cadernos da Escola do Legislativo. Belo Horizonte, 3 (6).

(2003) A Totalidade do Diabo: como as formas geográficas difundem o capital e mudam as estruturas sociais. In: SANTOS, M. (Org.). Economia espacial: críticas e alternativas. 2. ed. São Paulo: Edusp. pp. 187-202.

. (2005). A urbanização brasileira. 5. ed. São Paulo: Edusp. (2008a). A Natureza do Espaço: Técnica e Tempo. Razão e Emoção. 4. ed. São Paulo: Edusp.

(2008b) Por uma outra globalização: do pensamento único à consciência universal. 15. ed. Rio de Janeiro: Record.

SANTOS, M.; SILVEIRA, M. L. (2005). O Brasil: Território e Sociedade no início do Século XXI. Rio de Janeiro: Editora Record.

SOUZA FILHO, C. F. M. de. (1999) Os direitos invisíveis. In: OLIVEIRA, F. de; PAOLI, M. C. (Orgs.) Os sentidos da democracia: políticas do dissenso e hegemonia global. Petrópolis, RJ: Vozes; Brasília: NEDIC.

UNIÃO NACIONAL POR MORADIA POPULAR. (2008) Manifesto da Jornada pelo Direito à Moradia. Disponível em: http://unmp.org.br/index.php?option=com_content\&view=article\&id=63: manifesto-da-jornada-nacional-pelo-direito-a-moradiamaio08\&catid=53:mobilizacoes\&Itemid=74. Acessado em: 16 jan. 2009.

Data de submissão: 06/12/2014.

Data de aceite: 04/05/2015. 